\title{
ON THE STABILITY OF METRIC SEMIGROUP HOMOMORPHISMS
}

\author{
HAMID REZAEI AND SOON-MO JUNG
}

Abstract. In this paper, we investigate the stability of the homomorphism equation $f\left(x \circ_{1} y\right)=$ $f(x) \circ_{2} f(y)$ between semigroups $\left(G_{1}, \circ_{1}\right)$ and $\left(G_{2}, \circ_{2}\right)$, where the binary operation $\circ_{i}$ is squaresymmetric on the set $G_{i}$ for $i=1,2$. Our results generalize the classical theorem of Hyers concerning the stability of the Cauchy additive equation.

Mathematics subject classification (2010): 39B82, 39B52, 47H10.

Keywords and phrases: Functional equation, Hyers-Ulam-stability, metric semigroup homomorphism, fixed point.

\section{REFERENCES}

[1] T. AOKI, On the stability of the linear transformation in Banach spaces, J. Math. Soc. Japan 2 (1950), 64-66.

[2] L. CAdariu And V. RAdu, On the stability of the Cauchy functional equation: a fixed point approach, Grazer Math. Ber. 346 (2004), 43-52.

[3] J. Chmielinski And J. TABor, On approximate solutions of the Pexider equation, Aequationes Math. 46 (1993), 143-163.

[4] S. Czerwik, Functional Equations and Inequalities in Several Variables, World Scientific, Hackensacks, New Jersey, 2002.

[5] J. Dixmier, $C^{*}$-Algebras, North-Holland Publ. Com., Amsterdam, New York and Oxford, 1977.

[6] D. H. Hyers, On the stability of the linear functional equation, Proc. Natl. Acad. Sci. USA 27 (1941), 222-224.

[7] D. H. Hyers, G. Is AC And Th. M. RAssias, Stability of Functional Equations in Several Variables, Birkhäuser, Boston, 1998.

[8] S.-M. Jung, Hyers-Ulam-Rassias Stability of Functional Equations in Nonlinear Analysis, Springer Optimization and Its Applications Vol. 48, Springer, New York, 2011.

[9] B. MARGolis AND J. B. DiAZ, A fixed point theorem of the alternative for contractions on a generalized complete metric space, Bull. Amer. Math. Soc. 74 (1968), 305-309.

[10] D. Minet And V. RADU, On the stability of the additive Cauchy functional equation in random normed spaces, J. Math. Anal. Appl. 343 (2008), 567-572.

[11] Z. Pales, P. Volkmann AND R. D. LuCE, Hyers-Ulam stability of functional equations with a square-symmetric operation, Proc. Natl. Acad. Sci. 95 (1998), 12772-12775.

[12] V. RADU, The fixed point alternative and the stability of functional equations, Fixed Point Theory. 4 (2003), 91-96.

[13] Th. M. Rassias, On the stability of the linear mapping in Banach spaces, Proc. Amer. Math. Soc. 72 (1978), 297-300.

[14] S. M. Ulam, A Collection of Mathematical Problems, Interscience Tracts in Pure and Applied Mathematics, No. 8, Interscience, New York, NY, USA, 1960. 